\title{
Treatment of dental complications in sickle cell disease.
}

Priti Mulimani

Melaka-Manipal Medical College

Samir K. Ballas

Thomas Jefferson University

Adinegara B L Abas

Melaka-Manipal Medical College

Laxminarayan Karanth

Melaka-Manipal Medical College

Follow this and additional works at: https://jdc.jefferson.edu/cardeza_foundation

Part of the Hematology Commons

Let us know how access to this document benefits you

\section{Recommended Citation}

Mulimani, Priti; Ballas, Samir K.; Abas, Adinegara B L; and Karanth, Laxminarayan, "Treatment of dental complications in sickle cell disease." (2016). Cardeza Foundation for Hematologic

Research. Paper 34.

https://jdc.jefferson.edu/cardeza_foundation/34

This Article is brought to you for free and open access by the Jefferson Digital Commons. The Jefferson Digital Commons is a service of Thomas Jefferson University's Center for Teaching and Learning (CTL). The Commons is a showcase for Jefferson books and journals, peer-reviewed scholarly publications, unique historical collections from the University archives, and teaching tools. The Jefferson Digital Commons allows researchers and interested readers anywhere in the world to learn about and keep up to date with Jefferson scholarship. This article has been accepted for inclusion in Cardeza Foundation for Hematologic Research by an authorized administrator of the Jefferson Digital Commons. For more information, please contact: JeffersonDigitalCommons@jefferson.edu. 


\section{(A) Cochrane Library}

Cochrane Database of Systematic Reviews

\section{Treatment of dental complications in sickle cell disease (Review)}

Mulimani P, Ballas SK, Abas ABL, Karanth L

Mulimani P, Ballas SK, Abas ABL, Karanth L.

Treatment of dental complications in sickle cell disease.

Cochrane Database of Systematic Reviews 2016, Issue 4. Art. No.: CD011633.

DOI: 10.1002/14651858.CD011633.pub2.

www.cochranelibrary.com 
TABLE OF CONTENTS

HEADER . . . . . . . . . . . . . . . . . . . . . . . . . . . . . . . . . . . . 1

ABSTRACT . . . . . . . . . . . . . . . . . . . . . . . . . . . . . . . . . . . . . . . . . . . . . . .

PLAIN LANGUAGE SUMMARY . . . . . . . . . . . . . . . . . . . . . . . . . . . . . . . . . . . . 2

BACKGROUND . . . . . . . . . . . . . . . . . . . . . . . . . . . . . . . . . . . . . . . . .

OBJECTIVES . . . . . . . . . . . . . . . . . . . . . . . . . . . . . . . . . . . . . . . . 44

METHODS . . . . . . . . . . . . . . . . . . . . . . . . . . . . . . . . . . . . . . . . .

RESULTS . . . . . . . . . . . . . . . . . . . . . . . . . . . . . . . . . . . . . . . 9

DISCUSSION . . . . . . . . . . . . . . . . . . . . . . . . . . . . . . . . . . . . . 9

AUTHORS' CONCLUSIONS . . . . . . . . . . . . . . . . . . . . . . . . . . . . . . . . . . . . 10

ACKNOWLEDGEMENTS . . . . . . . . . . . . . . . . . . . . . . . . . . . . . . . . . 10

REFERENCES . . . . . . . . . . . . . . . . . . . . . . . . . . . . . . . . . . . . . . 10

DATA AND ANALYSES . . . . . . . . . . . . . . . . . . . . . . . . . . . . . . . . . . . . . . . .

APPENDICES . . . . . . . . . . . . . . . . . . . . . . . . . . . . . . . . . . . . . . . . . . . .

CONTRIBUTIONS OF AUTHORS . . . . . . . . . . . . . . . . . . . . . . . . . . . . . . . . . . . . . . . . . .

DECLARATIONS OF INTEREST . . . . . . . . . . . . . . . . . . . . . . . . . . . . . . . . . . . . 16

SOURCES OF SUPPORT . . . . . . . . . . . . . . . . . . . . . . . . . . . . . . . . . . 16 


\title{
[Intervention Review]
}

\section{Treatment of dental complications in sickle cell disease}

\author{
Priti Mulimani ${ }^{1}$, Samir K Ballas ${ }^{2}$, Adinegara BL Abas ${ }^{3}$, Laxminarayan Karanth ${ }^{4}$ \\ ${ }^{1}$ Department of Orthodontics, Melaka-Manipal Medical College, Malaysia, India. ${ }^{2}$ Cardeza Foundation for Hematologic Research, \\ Department of Medicine, Jefferson Medical College, Thomas Jefferson University, Philadelphia, USA. ${ }^{3}$ Department of Community \\ Medicine, Melaka-Manipal Medical College, Melaka, Malaysia. ${ }^{4}$ Department of Obstetrics and Gynecology, Melaka Manipal Medical \\ College, Melaka, Malaysia \\ Contact address: Priti Mulimani, Department of Orthodontics, Melaka-Manipal Medical College, Jalan Batu Hampar, Bukit Baru, \\ Malaysia, 75150, India. mulimanipriti@gmail.com.
}

Editorial group: Cochrane Cystic Fibrosis and Genetic Disorders Group.

Publication status and date: New, published in Issue 4, 2016.

Review content assessed as up-to-date: 21 April 2016.

Citation: Mulimani P, Ballas SK, Abas ABL, Karanth L. Treatment of dental complications in sickle cell disease. Cochrane Database of Systematic Reviews 2016, Issue 4. Art. No.: CD011633. DOI: 10.1002/14651858.CD011633.pub2.

Copyright (C) 2016 The Cochrane Collaboration. Published by John Wiley \& Sons, Ltd.

\begin{abstract}
A B S T R A C T
Background

Sickle cell disease is the most common single gene disorder and the commonest haemoglobinopathy found with high prevalence in many populations across the world. Management of dental complications in people with sickle cell disease requires special consideration for three main reasons. Firstly, dental and oral tissues are affected by the blood disorder resulting in several oro-facial abnormalities. Secondly, living with a haemoglobinopathy and coping with its associated serious consequences may result in individuals neglecting their oral health care. Finally, the treatment of these oral complications must be adapted to the systemic condition and special needs of these individuals, in order not to exacerbate or deteriorate their general health.

Guidelines for the treatment of dental complications in this population who require special care are unclear and even unavailable in many aspects. Hence this review was undertaken to provide a basis for clinical care by investigating and analysing the existing evidence in the literature for the treatment of dental complications in people with sickle cell disease.
\end{abstract}

\section{Objectives}

To assess methods of treating dental complications in people with sickle cell disease.

\section{Search methods}

We searched the Cochrane Haemoglobinopathies Trials Register, compiled from electronic database searches and handsearching of journals and conference abstract books.

Date of last search: 11 April 2016.

Additionally, we searched nine online databases (PubMed, Google Scholar, ClinicalTrials.gov, WHO International Clinical Trials Registry Platform, Literature in the Health Sciences in Latin America and the Caribbean database, African Index Medicus, Index Medicus for South East Asia Region, Index Medicus for the Eastern Mediterranean Region, Indexing of Indian Medical Journals). We also searched the reference lists of relevant articles and reviews and contacted haematologists, experts in fields of dentistry, organizations, pharmaceutical companies and researchers working in this field.

Date of last search: 03 March 2016.

Treatment of dental complications in sickle cell disease (Review)

Copyright @ 2016 The Cochrane Collaboration. Published by John Wiley \& Sons, Ltd. 


\section{Selection criteria}

We searched for published or unpublished randomised controlled studies of treatments for dental complications in people with sickle cell disease.

\section{Data collection and analysis}

Two review authors intended to independently extract data and assess the risk of bias of the included studies using standard Cochrane methodologies; however, no studies were identified for inclusion in the review.

\section{Main results}

No randomised controlled studies were identified.

\section{Authors' conclusions}

This Cochrane review did not identify any randomised controlled studies assessing interventions for the treatment of dental complications in people with sickle cell disease. There is an important need for randomised controlled studies in this area, so as to identify the most effective and safe method for treating dental complications in people with sickle cell disease.

\section{PLAIN LANGUAGE SUMMARY}

\section{Treatment of dental complications in sickle cell disease}

\section{Review question}

We planned to review the evidence regarding the treatment of dental complications in people with sickle cell disease.

\section{Background}

Sickle cell disease is a blood disorder which affects at least $5.2 \%$ of the world population across a large number of countries. In this condition, a genetic defect means that the haemoglobin in the red blood cells is not normal, instead the blood cells become sickleshaped and not a normal disc shape. These cells become trapped in blood vessels of various organs, especially during stressful events like a lack of oxygen, dehydration, extreme temperatures, stress, menstruation and infection. Blocked blood vessels lead to sudden episodes of severe pain in the short term and chronic organ damage in the long term.

Sickle cell disease also leads to changes and complications in the mouth, jaw and facial areas. Management of these dental complications is often neglected as people with sickle cell disease focus all their energy on maintaining their general health due to the serious blood disorder. Neglecting minor dental health issues under these circumstances not only worsens the problem but may also cause a painful sickle-cell crisis, leading to emergency hospital admissions. Treatment of oral complications in this group of people needs to be tailored around their blood disorder, in order not to cause any further deterioration to their general health.

There is a lack of information on the appropriate treatment for dental complications in people with sickle cell disease,with no clear guidelines available. This often results in many people being refused treatment by dentists due to a fear of complications. Hence, we planned to investigate this issue and make any evidence in this area available to healthcare providers and people with the disease.

\section{Search date}

The evidence is current to: 03 March 2016.

\section{Study characteristics}

We were not able to find any randomised controlled studies assessing treatment for any dental complications in people with sickle cell disease.

\section{Key results}

No studies were identified, so we can not draw any conclusions or highlight any implications for practice. Studies are needed to establish the best treatment for dental problems in people with sickle cell disease.

\section{Quality of the evidence}

Treatment of dental complications in sickle cell disease (Review)

Copyright @ 2016 The Cochrane Collaboration. Published by John Wiley \& Sons, Ltd. 
There is no evidence from studies (where people are given one treatment or another completely at random) for any treatment for dental complications in people with sickle cell disease.

\section{B A C K G R O U N D}

For an explanation of terms, please refer to the glossary (Appendix $1)$.

\section{Description of the condition}

Problems in oral and dental health commonly experienced by most individuals result from chronic, degenerative, pathological changes accompanied by intermittent, recurrent, acute episodes in dental tissues and supporting structures. As dental health problems are not life-threatening, both individuals and non-oral healthcare providers consider these a minor inconvenience and the changes in behaviour required to deal with them as trivial. Fear of dental treatment and the expense which treatment incurs play a further inhibitory role among those seeking treatment for dental complications. In turn, this has significant social, functional and economic costs as seen in the 1981 National Health Interview Survey in the USA, where 4.87 million dental conditions caused 17.7 million days of restricted activity, 6.73 million days of bed disability, and 7.05 million days of work loss (Reisine 1985). People dealing with more pressing and life-threatening medical conditions, such as haemoglobinopathies, may not regard oral health as a priority and in some cases may completely neglect it, especially those from low socio-economic status groups. This often results in such people arriving in hospital emergency departments with dental complications and may warrant further hospital admission to manage associated complications (Laurence 2013).

Haemoglobinopathies are a group of autosomal recessive disorders affecting the structure and synthesis of haemoglobin. Mutations in the genes of these chains give rise to conditions such as sickle cell disease (SCD) and the thalassaemias. This review will focus on SCD which is one of the most common haemoglobin disorders as well as one of the most common single-gene disorders in the world (Colledge 2010; Fonseca 2007). Haemoglobinopathies were previously highly region-specific with a predilection amongst African, Mediterranean, Middle-Eastern, South-East Asian and Indian subcontinental groups. However, widespread global migration has resulted in them affecting at least $5.2 \%$ of the global population. Annually there are over 332,000 affected conceptions or births, of which 275,000 are affected by SCD requiring early diagnosis and prophylaxis (Modell 2008).

Sickle cell disease comprises a group of clinically significant qualitative haemoglobin $(\mathrm{Hb})$ disorders, in which the sickle gene is inherited from at least one parent. The sickle mutation itself is the result of a single base change (GAT $\rightarrow$ GTT) in the sixth codon of exon 1 of the $\beta$-globin gene on short arm of chromosome 11, responsible for the synthesis of the $\beta$-globin polypeptide of the $\mathrm{Hb}$ molecule $(\alpha 2 \beta 2)$. This change, in turn, results in replacement of the normal glutamic acid with valine at position 6 of the $\beta$-globin chain and the formation of sickle Hb. Sickle cell anaemia (SCA) is the homozygous state, where the sickle gene is inherited from both parents. Other sickle cell disorders result from the co-inheritance of the sickle cell gene with the gene of other abnormal haemoglobin such as $\mathrm{Hb} \mathrm{C}, \mathrm{Hb} \mathrm{D}$ or HbO-Arab, giving rise to Hb SC disease, $\mathrm{Hb} \mathrm{SD}$ disease or $\mathrm{Hb} \mathrm{SO}-\mathrm{Arab}$ disease respectively. Moreover, the co-inheritance of the sickle gene with thalassaemia genes $(\beta$ ${ }^{0}$ or $\beta^{+}$) results in sickle- $\beta^{0}$-thalassemia or sickle- $\beta^{+}$-thalassaemia respectively. In SCD, amino acid substitution causes $\mathrm{HbS}$ to polymerise intracellularly when deoxygenated, thus changing the biconcave discoid shape of red blood cells (RBCs) to sickle shapes. Sickling is precipitated by hypoxia, extreme temperatures, dehydration, physical or emotional stress, menstruation and infection. The sickled cells tend to have a shorter survival rate and plug vessels in microcirculation leading to acute syndromes such as vasoocclusive crises (VOCs), sickle chest syndrome, aplastic crisis and sequestration crisis; in the long term these are followed by chronic organ damage (Fonseca 2007; Ingram 1957).

Clinical features of SCD include pain episodes, anaemia of variable severity, organ damage and infection. Pain, however, is the hallmark of SCD in general and SCA in particular and it is the most important aspect of its clinical picture. All body organs are affected, or are at risk of being affected, by SCD. The complications of most major organs such as the brain, lungs, liver and kidney are relatively well known and described in the literature. Treatment of dental complications, however, has not been well addressed. Common dental complications described in SCD include caries or cavities, tooth hypomineralisation, orofacial pain, neuropathy, facial swelling, pallor of oral mucosa, malocclusions, infections, pulpal necrosis, cortical erosions, medullary hyperplasia and abnormal trabecular spacings (Andrews 1983; Ballas 2014; Demirbas Kaya 2004; Fonseca 2007; Friedlander 1980; Mendes 2011; Scipio 2001; Soni 1966; Taylor 1995). Studies have shown that individuals with SCD have a greater risk of developing a general or dental infection, commonly of unknown origin, as compared to controls; and these dental infections could, in turn, in some cases be responsible for precipitating sickle cell crises (O’Rourke 1990; 
Rada 1987). Most providers know that dental complications such as infections (gingivitis, periodontitis) and caries are factors that precipitate VOCs. Dental infection through inflammatory mediators could potentially trigger or exacerbate an already existing crisis leading to increased hospital admissions (Laurence 2013).

\section{Description of the intervention}

Dental treatment for people with SCD should be designed keeping in mind both their general health and the possible impact of the dental procedures on their pre-existing systemic condition. Prophylactic antibiotics are administered to prevent the precipitation of VOCs or systemic infections as a result of dental infections or surgical treatment procedures. Local anaesthetic, conscious sedation, anxiolytics and sedatives to alleviate anxiety are also used to avoid the precipitation of stress or pain-related crises. Antidepressants, anticonvulsants and clonidine are used for treating neuropathic pain (Fonseca 2007; Piccin 2008). For dental procedures requiring intravenous sedation or general anaesthesia, individuals are referred to hospitals with haematology expertise and care is taken to keep the person well-hydrated and warm, with oxygen therapy administered during and immediately after the procedure. To correct malocclusion, orthodontic treatment is carried out using light forces and increased periods of rest during tooth movement, while monitoring bone response, pulpal health and the systemic condition (Fonseca 2007; Rinchuse 2007; Zahrowski 2009).

\section{How the intervention might work}

Splenic function is reduced in people with SCD, thus reducing their immunity especially against encapsulated bacteria and increasing their susceptibility to infection. Vaccinations against Pneumococcus pneumoniae can prevent the most frequent systemic complications in these individuals. By the same rationale, antibiotic prophylaxis before invasive dental surgical procedures is recommended to prevent local or systemic infections and the precipitation of crises in people with SCD. Conscious sedation, prescription of anxiolytics and scheduling of dental appointments during chronic phases may alleviate stress and prevent treatment-related sickle cell crises. Orthodontic treatment is carried out using light forces and with appropriate intervals of rest in order to avoid or minimize pain, crises or infections during the procedure (Alves 2006).

\section{Why it is important to do this review}

Oral health issues or dental problems can no longer be considered as isolated, random, mutually exclusive occurrences, but instead need to be seen as an integral part of a complex holistic physiological apparatus, where dysfunction in one system could simul- taneously be a cause as well as an effect of disturbance in other intricately linked systems (Wison Schaeffer 1999). A lack of understanding of this intimate relationship between oral and general health among lay and medical people alike has led to the exclusion of oral health as an important traditional clinical indicator of general health and well-being. This is prominently observed among people with special needs and medically compromised conditions (like SCD) who are not only predisposed to dental pathologies, but whose treatment also needs special consideration. This results in many of these people being refused treatment by dentists due to fear of trans- and post-operative complications which they are unable or unequipped to deal with. This could also be attributed to lack of clinical guidelines, awareness and training or sufficient information, research or data in the literature to enable healthcare providers to handle such cases confidently and successfully (Laurence 2006; Passos 2012).

Haemoglobin disorders, having lost their regional specificity, are now a global concern. In poorer countries, improved hygiene, nutrition and public health ensure reduced levels of infant and childhood mortality, which means more infants with SCD are surviving and presenting for treatment later in life. This poses a challenge to public health resources and the expertise of the medical community in handling and treating them, prompting the issue to be labelled as an "emerging global health burden" (Edwards 2005; Reisine 1985; Weatherall 2010). It is the intention of this review to comprehensively explore the literature and look for clinically useful evidence for the treatment of dental complications and thus improve the oral health-related quality of life (OHQoL) of people with SCD.

\section{O B J E C T I VES}

The main objectives of this review are to assess methods to treat dental complications in people with SCD. The terminology 'dental complications' is used to represent all oral infections, diseases and conditions affecting the teeth, jaws, orofacial region and associated structures, such as dental caries, periodontal disease, odontogenic infections, osteomyelitis, cellulitis, craniofacial deformities and malocclusion.

\section{METHODS}

\section{Criteria for considering studies for this review}

\section{Types of studies}

Randomised controlled trials (RCTs) and quasi-RCTs. 


\section{Types of participants}

All children and adults diagnosed with SCD irrespective of phenotype, severity, age, gender and ethnic origin.

\section{Types of interventions}

We planned to consider any study which included one or more of the following interventions being compared with either placebo, no treatment or an alternative treatment in the treatment of dental complications.

1. Management of dental pain using analgesics and alternative techniques, e.g. acupressure, relaxation and Reiki.

2. Prevention of sickle cell crises during treatment (using preoperative analgesics, anxiolytics, conscious sedation and prophylactic antibiotics).

3. Application of light forces, non-extraction mechanics and modification of treatment according to bone and systemic conditions during orthodontic therapy.

4. Early intervention and minimally invasive techniques for caries management.

\section{Types of outcome measures}

\section{Primary outcomes}

1. Resolution or reduction in the severity of the condition (as measured by)

i) decayed, missing, filled teeth (DMFT) index, radiographic changes, salivary acid or streptococcus mutans levels for dental caries

ii) gingival or plaque indices, probing depth, bone level for periodontal diseases

iii) change in teeth or jaw positions, cephalometric analysis, malocclusion indices (in case of malocclusions and craniofacial deformities)

iv) visual analogue scale, dichotomy scale or Likert scale for pain assessment

v) any other relevant measure reported

\section{Secondary outcomes}

1. Adverse incidents consequent to treatment, e.g. systemic infections, impairment or loss of oral function, iatrogenic damage during treatment like pulpal necrosis, root resorption or bone loss

2. Sickle cell crises due to dental complications in individuals with SCD

3. Health service utilisation

i) frequency of emergency department visits and hospital admissions

ii) duration of hospitalisations iii) consultations with practitioners

4. Quality of life (physical and social function, ability to fulfil roles, life satisfaction) as measured using a validated scoring system such as Health Status Survey Short Form (SF-36), the Profile of Mood Status (POMS), Child Health QuestionnaireParent Report Form or any other

5. Economic effects (e.g. loss or change of job, number of days off work or school, treatment cost)

\section{Search methods for identification of studies}

We attempted to identify all relevant studies regardless of language and status of publication.

\section{Electronic searches}

We searched for relevant studies from the Cystic Fibrosis and Genetic Disorders Group's Haemoglobinopathies Trials Register using the term: dental AND (sickle cell disease OR haemoglobinopathies general).

The Haemoglobinopathies Trials Register is compiled from electronic searches of the Cochrane Central Register of Controlled Trials (CENTRAL) (updated each new issue of The Cochrane Library) and weekly searches of MEDLINE. Unpublished work is identified by searching the abstract books of five major conferences: the European Haematology Association conference; the American Society of Hematology conference; the British Society for Haematology Annual Scientific Meeting; the Caribbean Health Research Council Meetings; and the National Sickle Cell Disease Program Annual Meeting. For full details of all searching activities for the register, please see the relevant section of the Cochrane Cystic Fibrosis and Genetic Disorders Group Module.

Date of latest search: 04 April 2016.

We also searched PubMed (www.ncbi.nlm.nih.gov/pubmed) and Google Science (scholar.google.com/)

Date of latest search: 03 March 2016.

We also searched the following registries of ongoing clinical studies from date of inception for evidence of unpublished studies and protocols of published studies:

- ClinicalTrials.gov (ClinicalTrials.gov);

- WHO International Clinical Trials Registry Platform ( www.who.int/ictrp/search/en/);

- Literature in the Health Sciences in Latin America and the Caribbean database (LILACS) (lilacs.bvsalud.org/en/);

- African Index Medicus (AIM 2002) (

indexmedicus.afro.who.int/)

- Index Medicus for South East Asia Region ( imsear.hellis.org/);

- Index Medicus for the Eastern Mediterranean Region ( www.emro.who.int/information-resources/imemr/imemr.html);

- Indexing of Indian Medical Journals (www.indmed.nic.in/).

Treatment of dental complications in sickle cell disease (Review) 
For more details of the individual search strategies, please refer to the appendices (Appendix 2).

Date of latest search: 03 March 2016.

\section{Searching other resources}

We intended to scrutinize the reference lists of the identified studies for additional citations and also to cross-check references from any obtained studies to identify more studies. We contacted haematologists, experts in different fields of dentistry, organizations and researchers working in this field. We also contacted pharmaceutical companies for information on unpublished and ongoing studies.

\section{Data collection and analysis}

No studies were available for inclusion. The following methods will be employed should studies be included in future updates of this review.

\section{Selection of studies}

Two review authors (PM, SB) will independently assess for inclusion all the potential studies identified as a result of the searches. We will resolve any disagreement through discussion or, if required, we will consult a third person (ABL).

We will include studies published only in abstract form if they otherwise satisfy the review's inclusion criteria. We will contact the authors of such studies if we require any additional information.

\section{Data extraction and management}

We will design a form to record any extracted data from eligible studies. Two review authors (PM, LK) will independently extract the following information from any included studies.

1. Methods: study design; total duration of study; study location; study setting; withdrawals; and date of study.

2. Participants: number enrolled; mean age or age range; gender; severity of condition; diagnostic criteria if applicable; inclusion and exclusion criteria.

3. Interventions: description of intervention; comparison; duration; intensity; content of both intervention and control condition; and co-interventions.

4. Outcomes: description of primary and secondary outcomes specified and collected, and at which time points reported.

5. Notes: funding for trial, and notable conflicts of interest of trial authors.

We will resolve discrepancies through discussion or, if required, we will consult a third or fourth person (SB, ABL). We will enter the data into the Review Manager software and check for accuracy (RevMan 2014). When information regarding any of the above is unclear, we will attempt to contact authors of the original reports to provide further details.

\section{Assessment of risk of bias in included studies}

Two review authors (PM, $\mathrm{ABL}$ ) will independently assess the risk of bias for each study using the criteria outlined in the Cochrane Handbook for Systematic Reviews of Interventions (Higgins 2011). We will resolve any disagreement by discussion or by involving a third assessor (LK).

\section{Random sequence generation (checking for possible selection bias)}

For each included study, we will describe the method used to generate the allocation sequence in sufficient detail to allow an assessment of whether it should produce comparable groups. We will assess the method as:

- low risk of bias (any truly random process, e.g. random number table; computer random number generator);

- high risk of bias (any non-random process, e.g. odd or even date of birth; hospital or clinic record number);

- unclear risk of bias.

\section{Allocation concealment (checking for possible selection bias)}

For each included study, we will describe the method used to conceal the allocation to interventions prior to assignment and will assess whether this allocation could have been foreseen in advance of, or during recruitment, or changed after assignment. We will assess the methods as:

- low risk of bias (e.g. telephone or central randomisation; consecutively numbered sealed opaque envelopes);

- high risk of bias (open random allocation; unsealed or nonopaque envelopes, alternation; date of birth);

- unclear risk of bias.

\section{Blinding}

\section{1. of participants and personnel (checking for possible performance bias)}

For each included study, we will describe the methods used, if any, to blind study participants and personnel from knowledge of which intervention a participant received. We will consider that studies are at low risk of bias if they were blinded, or if we judge that the lack of blinding would be unlikely to affect results. We will assess blinding separately for different outcomes or classes of outcomes. We will assess the methods as:

- low, high or unclear risk of bias for participants;

- low, high or unclear risk of bias for personnel.

Treatment of dental complications in sickle cell disease (Review) 


\section{2. of outcome assessment (checking for possible detection bias)}

For each included study, we will describe the methods used, if any, to blind outcome assessors from knowledge of which intervention a participant received. We will assess blinding separately for different outcomes or classes of outcomes. We will assess methods used to blind outcome assessment as:

- low risk of bias;

- high risk of bias;

- unclear risk of bias.

\section{Incomplete outcome data (checking for possible attrition bias due to the amount, nature and handling of incomplete outcome data)}

For each included study and for each outcome or class of outcomes, we will describe the completeness of data including attrition and exclusions from the analysis. We will state whether attrition and exclusions were reported and the numbers included in the analysis at each stage (compared with the total randomised participants), reasons for attrition or exclusion where reported, and whether missing data were balanced across groups or were related to outcomes. Where sufficient information is reported, or can be supplied by the study authors, we will re-include missing data in the analyses which we undertake. We will assess methods as:

- low risk of bias (e.g. no missing outcome data; missing outcome data balanced across groups);

- high risk of bias (e.g. numbers or reasons for missing data imbalanced across groups; 'as treated' analysis done with substantial departure of intervention received from that assigned at randomisation);

- unclear risk of bias.

In case of missing data we will take the following steps:

- if possible, contact the original investigators to request missing data;

- make explicit any assumptions we make to deal with missing data, for example, if we assume that the data are missing at random, or if we assume that missing data have a particular value such as a poor outcome;

- perform sensitivity analyses to assess how sensitive results are to reasonable changes in the assumptions that are made;

- address the potential impact of missing data on the findings of the review in the 'Discussion' section.

\section{Selective reporting (checking for reporting bias)}

For each included study, we will describe how we investigated the possibility of selective outcome reporting bias and what we found. We will assess the methods as:

- low risk of bias (where it is clear that all of the study's prespecified outcomes and all expected outcomes of interest to the review have been reported);
- high risk of bias (where not all the study's pre-specified outcomes have been reported; one or more reported primary outcomes were not pre-specified; outcomes of interest are reported incompletely and so cannot be used; study fails to include results of a key outcome that would have been expected to have been reported);

- unclear risk of bias.

\section{Other bias (checking for bias due to problems not covered by (I) to (5) above)}

For each included study, we will describe any important concerns we have about other possible sources of bias. We will assess whether each study was free of other problems that could put it at risk of bias:

- low risk of other bias;

- high risk of other bias;

- unclear whether there is risk of other bias.

\section{Overall risk of bias}

We will make explicit judgements about whether studies are at high risk of bias, according to the criteria given in the Cochrane Handbook for Systematic Reviews of Interventions (Higgins 2011). With reference to points 1 to 6 above, we will assess the likely magnitude and direction of the bias and whether we consider it is likely to impact on the findings. We will explore the impact of the level of bias through undertaking sensitivity analyses

\section{Measures of treatment effect}

For dichotomous data (e.g. adverse effects), we will present results as a summary risk ratio (RR) with $95 \%$ confidence intervals (CIs). For continuous data (e.g. number of decayed, missing or filled teeth), we will use the mean difference (MD) and 95\% CIs if outcomes are measured in the same way between studies. We will use the standardised mean difference (SMD) to combine studies that measure the same outcome, but use different units of measurement.

We will calculate the events occurring more than once per person as the number of counts and treated in the same way as continuous outcome data. We will present the MD and compare the difference in the mean number of events (standardized to a unit time period) experienced by participants in the intervention group compared with participants in the control group (Deeks 2011).

\section{Unit of analysis issues}

We will include cluster-randomised studies in the analyses along with individually randomised studies. We will adjust their sample sizes by methods using an estimate of the intra-cluster correlation co-efficient (ICC) derived from the study (if possible), or from another source. If we use ICCs from other sources, we will report 
this and conduct sensitivity analyses to investigate the effect of variations in the ICC. If we identify both cluster-randomised studies and individually randomised studies, we plan to synthesise the relevant information. We will consider it reasonable to combine the results from both types of study if there is little heterogeneity between the study designs and the interaction between the effect of intervention and the choice of randomisation unit is considered to be unlikely. We will also acknowledge heterogeneity in the randomisation unit and perform a separate meta-analysis. Therefore, we will perform the meta-analysis in two parts.

\section{Dealing with missing data}

For included studies, we will note levels of attrition. We will explore the impact of including studies with high levels of missing data in the overall assessment of treatment effect by using a sensitivity analysis. For all outcomes, we will carry out analyses (as far as possible) on an intention-to-treat basis, i.e. we will attempt to include all participants randomised to each group in the analyses, and all participants will be analysed in the group to which they were allocated, regardless of whether or not they received the allocated intervention. The denominator for each outcome in each study will be the number randomised minus any participants whose outcomes are known to be missing. We will exclude studies with more than $20 \%$ missing data. We will also perform sensitivity analyses to assess how sensitive results are to reasonable changes in the assumptions that we make.

\section{Assessment of heterogeneity}

We will assess methodological heterogeneity by examining the risk of bias of any included trial. We will assess statistical heterogeneity among studies by visually inspecting the forest plots and using the $\mathrm{Chi}^{2}$ test and $\mathrm{I}^{2}$ statistic for heterogeneity with a statistical significance level of $\mathrm{P}$ value $<0.10$. For the interpretation of the I 2 values, we will use the following guidelines (Higgins 2011):

- $0 \%$ to $40 \%$ : might not be important;

- $30 \%$ to $60 \%$ : may represent moderate heterogeneity;

- $50 \%$ to $90 \%$ : may represent substantial heterogeneity;

- $75 \%$ to $100 \%$ : considerable heterogeneity.

If we identify substantial heterogeneity, we will report it and explore possible causes by subgroup analysis.

\section{Assessment of reporting biases}

If there are 10 or more studies in the meta-analysis, we will investigate reporting biases (such as publication bias) using funnel plots. We will assess funnel plot asymmetry visually and if this suggests there is asymmetry, we will perform exploratory analyses to investigate this as detailed in the Cochrane Handbook for Systematic Reviews of Interventions (Sterne 2011).

\section{Data synthesis}

We will carry out statistical analysis using the Review Manager software (RevMan 2014). We will use a fixed-effect meta-analysis for combining data where it is reasonable to assume that studies are estimating the same underlying treatment effect, i.e. where studies are examining the same intervention, and the study populations and methods are judged sufficiently similar. If there is clinical heterogeneity sufficient to expect that the underlying treatment effects will differ between studies, or if substantial statistical heterogeneity is detected and a pooled treatment effect across studies is still considered clinically meaningful, we will use a random-effects meta-analysis to produce an overall summary and discuss the clinical implications of treatment effects differing between studies. If we use a random-effects analysis, we will present the results as the pooled treatment effect with $95 \%$ CIs and the estimates of $\mathrm{I}^{2}$. If the pooled treatment effect is not clinically meaningful, we will not combine studies.

\section{Subgroup analysis and investigation of heterogeneity}

If we identify substantial heterogeneity, we will investigate it using subgroup analyses. We will consider whether an overall summary is meaningful, and if so we will use a random-effects analysis to produce it. We plan to carry out the following subgroup analyses:

- male versus female participants;

- different ages paediatric (up to 18 years of age) versus adult (18 years and over);

- different types of SCD.

We will assess subgroup differences using interaction tests available within the Review Manager software (RevMan 2014). We will report the results of the subgroup analyses quoting the $\mathrm{Chi}^{2}$ test and $\mathrm{P}$ value, and the interaction test $\mathrm{I}^{2}$ value.

\section{Sensitivity analysis}

We will perform sensitivity analyses for aspects of the review that might affect the results; for example, where there is a risk of bias associated the included studies. We will undertake analysis of the primary outcome separately for studies with a low risk of bias and a high or unknown risk of bias for allocation concealment. We will explore the impact of including studies with high levels of missing data in the overall assessment of treatment effect and also to assess how sensitive results are to reasonable changes in the assumptions that are made on missing data. We will also carry out a sensitivity analysis to explore the effects of random-effects analyses for outcomes with statistical heterogeneity. We will also conduct sensitivity analyses to investigate the effect of variations in any ICCs we have used. 


\section{Summary of findings table}

We will create a 'Summary of findings' table for each comparison using the following outcomes.

1. Resolution or reduction in the severity of the condition

2. Adverse incidents consequent to treatment

3. Health service utilisation

We will use the five GRADE considerations (study limitations, consistency of effect, imprecision, indirectness and publication bias) to assess the quality of a body of evidence as it relates to the studies which contribute data to the meta-analyses for the prespecified outcomes. We will use methods and recommendations described in section 8.5 and chapter 12 of the Cochrane Handbook for Systematic Reviews of Interventions using GRADEpro software (Higgins 2011; Schünemann 2011). We will justify all decisions to down- or upgrade the quality of studies using footnotes and we will make comments to aid the reader's understanding of the review where necessary.

\section{RE S U L T S}

\section{Description of studies}

\section{Results of the search}

The searches did not identify any RCTs or quasi-RCTs eligible for inclusion in this Cochrane review (nor any that were potentially eligible); we were not able to identify any ongoing studies.

\section{Risk of bias in included studies}

The searches did not identify any RCTs or quasi-RCTs eligible for inclusion in this Cochrane review (nor any that were potentially eligible).

\section{Effects of interventions}

The searches did not identify any RCTs or quasi-RCTs eligible for inclusion in this Cochrane review (nor any that were potentially eligible), nor were we able to identify any ongoing trials.

\section{DISCUSSION}

\section{Summary of main results}

Despite undertaking an extensive search of the literature (electronic searching, handsearching and identifying ongoing trials), no randomised controlled trials (RCTs) were identified which met the inclusion criteria for this review.

\section{Potential biases in the review process}

This Cochrane review contains no studies and as such, no risk of bias could be evaluated. it is possible that trials with negative results may have remained unpublished. In spite of the extensive search carried out, no RCTs were available for inclusion. The main limitation of this Cochrane review is the paucity of evidence for treatment of dental complications in people with sickle cell disease (SCD).

\section{Agreements and disagreements with other studies or reviews}

Due to the absence of evidence from RCTs or quasi-RCTs, we were unable to compare our results with other published systematic reviews or excluded studies. During our search, we did identify a small body of mid-level evidence derived from observational studies such as cohort, case-control and cross-sectional sectional studies, but most of these report incidences or prevalences of dental diseases and their impact on people with SCD compared to healthy controls and do not investigate any intervention for treating these complications. Furthermore the bulk of the evidence in this area is of low level, derived mostly from retrospective studies, case reports and expert opinion articles which consist predominantly of descriptive narrations of the pathological changes in the oral-dental-craniofacial region, general principles of treatment and specific interventions in cases encountered. A condensed summary of available information derived from these sources follows.

Two studies recommended that if individuals are experiencing a vaso-occlusive crisis, only emergency relief of pain and infection is indicated. Infections should be treated with antibiotics and definitive treatment postponed until the crisis subsides (Hammersley 1984; Rouse 1979). A retrospective study reported successfully performing outpatient procedures without any complications in people with SCD by administering 2\% lignocaine with 1:100,000 epinephrine (Stanley 2013). Acetaminophen or codeine were recommended for post-operative pain control, but aspirin was not recommended due to its possible adverse effect on platelet function resulting in increased bleeding, acid-base balance and bone marrow suppression (Smith 1986). In cases of osteomyelitis in the posterior mandibular region, treatment may include sequestrectomy, curettage, debridement, corticotomy and resection of mandible and affected muscles with appropriate antibiotic coverage and following the surgical principles recommended for people with SCD (Hammersley 1984; Lawrenz 1999; Shroyer 1991). The $2014 \mathrm{ev-}$ idence-based expert panel report on SCD recommends using red

Treatment of dental complications in sickle cell disease (Review) 
blood cell transfusion to bring preoperative haemoglobin levels to $10 \mathrm{~g} / \mathrm{dL}$ prior to any surgical procedures involving general anaesthesia (Yawn 2014).

Avascular pulpal necrosis in clinically intact teeth was a common finding in people with SCD; hence, a routine evaluation of pulp in clinically intact teeth was recommended (Costa 2013). Root canal therapy must be carried out to satisfactory technical standard and antibiotic prophylaxis may be required; this therapy may also cause a sickle cell crisis (Gregory 1994).

A study has reported that $30.1 \%$ of individuals with SCD had indications for mandatory orthodontic treatment as compared to only $2.7 \%$ of the controls (Costa 2013). Orthodontic treatment in people with SCD was considered to be elective (Sams 1990); however successful treatment with fixed appliances in conjunction with extractions and extraoral orthopedic appliances has been reported (Oluwatosin 2009; Pithon 2011).

Prevention of dental complications is considered the best approach in people with SCD. It is recommended that periodic dental screening should be provided as part of their general physical examination. Incorporating fluorides, maintaining oral hygiene, routine dental visits and treating dental issues as soon as they are detected are measures which can reduce complications (Demas 1988; Javed 2013; Rouse 1979).

\section{A U THORS' CONCLUSIONS}

\section{Implications for practice}

This systematic review did not identify any RCTs or quasi-RCTs to guide treatment of dental complications in people with SCD. Accordingly, we are unable to evaluate the effects of any interventions. In the absence of high quality evidence, clinicians need to use their clinical judgement and refer to lower level evidence (e.g. observational studies, case reports, expert opinion) for selecting the best and most suitable form of intervention for treating the dental complications in people with SCD.

\section{Implications for research}

This Cochrane review has identified the need for well-designed, adequately powered RCTs to assess the effectiveness of treatments for dental complications in people with SCD.

\section{ACKNOWLEDGEMENTS}

We thank the Cystic Fibrosis and Genetic Disorders Review Group and its valuable members for providing us with the support and framework on which to carry out this review.

We also thank the institutional support and encouragement we received from Melaka-Manipal Medical College to enable us in writing this review.

\section{R E F E R E N C E S}

\section{Additional references}

Alves 2006

Alves PVM, Alves DKM, Gomes de Souza MM, Torres SR. Orthodontic treatment of patients with sickle-cell anemia. The Angle Orthodontist 2006;76(2):269-73.

\section{Andrews 1983}

Andrews CH, England MC, Kemp WB. Sickle cell anemia: an etiological factor in pulpal necrosis. Journal of Endodontics 1983;9(6):249-52.

Ballas 2014

Ballas SK, Lobo CLDC, Cavalcanti WE. Dental Complications of Sickle Cell Disease. Journal of Interdisciplinary Medicine and Dental Science 2014;2:152.

\section{Colledge 2010}

Colledge NR, Walker BR, Ralston SH. Davidson's Principles and Practice of Medicine. 21st Edition. Elsevier, 2010.

Costa 2013

Costa CP, Thomaz EB, Souza Sde F. Association between sickle cell anemia and pulp necrosis. Journal of Endodontics 2013;39(2):177-8.

\section{Deeks 2011}

Deeks J, Higgins J, Altman D, on behalf of the Cochrane Statistical Methods Group. Chapter 9 Analysing data and undertaking meta-analysis. In: Higgins JPT, Green S (editors). Cochrane Handbook for Systematic Reviews of Interventions Version 5.1.0 [updated March 2011]. The Cochrane Collaboration, 2011. Available from www.cochrane-handbook.org.

Demas 1988

Demas DC, Cantin RY, Poole A, Thomas HF. Use of general anesthesia in dental care of the child with sickle cell anemia. A case report. Oral Surgery, Oral Medicine, and Oral Pathology 1988;66(2):190-3.

\section{Demirbas Kaya 2004}

Demirbas Kaya A, Aktener BO, Unsal C. Pulpal necrosis with sickle cell anaemia. International Endodontic Journal 2004;37(9):602-6.

Edwards 2005

Edwards CL, Scales MT, Loughlin C, Bennett GG, HarrisPeterson S, De Castro LM, et al. A brief review of the pathophysiology, associated pain, and psychosocial issues

Treatment of dental complications in sickle cell disease (Review)

Copyright $\odot 2016$ The Cochrane Collaboration. Published by John Wiley \& Sons, Ltd. 
in sickle cell disease. International Journal of Behavioral Medicine 2005;12:171-9.

\section{Fonseca 2007}

Fonseca MA, Oueis HS, Casamassimo PS. Sickle cell anemia: a review for the pediatric dentist. Pediatric Dentistry 2007;29(2):156-69.

\section{Friedlander 1980}

Friedlander AH, Genser L, Swerdloff M. Mental nerve neuropathy: a complication of sickle-cell crisis. Oral Surgery 1980;49(1):15-7.

\section{Gregory 1994}

Gregory G, Olujohungbe A. Mandibuiar nerve neuropathy in sickle cell disease. Oral Surgery, Oral Medicine and Oral Pathology 1994;77:66-9.

\section{Hammersley 1984}

Hammersley N. Mandibular infarction occurring during sickle cell crisis. British Journal of Oral \& Maxillofacial Surgery 1984;22(2):103-14.

\section{Higgins 2011}

Higgins JPT, Altman DG, Sterne JAC (editors) on behalf of the Cochrane Statistical Methods Group and the Cochrane Bias Methods Group. Chapter 8: Assessing risk of bias in included studies. In: Higgins JPT, Green $S$ (editors). Cochrane Handbook for Systematic Reviews of Interventions Version 5.1.0 [updated March 2011]. The Cochrane Collaboration, 2011. Available from www.cochrane-handbook.org.

\section{Ingram 1957}

Ingram VM. Gene mutations in human haemoglobin: the chemical difference between normal and sickle cell haemoglobin. Nature 1957;180(4581):326-28.

\section{Javed 2013}

Javed F, Correa FO, Nooh N, Almas K, Romanos GE, AlHezaimi K. Orofacial manifestations in patients with sickle cell disease. American Journal of the Medical Sciences 2013; 345(3):234-7.

\section{Laurence 2006}

Laurence B, George D, Woods D, Shosanya A, Katz RV, Lanzkron $S$, et al. The association between sickle cell disease and dental caries in African Americans. Special Care in Dentistry 2006;26(3):95-100.

\section{Laurence 2013}

Laurence B, Haywood C Jr, Lanzkron S. Dental infections increase the likelihood of hospital admissions among adult patients with sickle cell disease. Community Dental Health 2013;30(3):168-72.

\section{Lawrenz 1999}

Lawrenz DR. Sickle cell disease: a review and update of current therapy. Journal of Oral and Maxillofacial Surgery 1999;57(2):171-8.

\section{Mendes 2011}

Mendes PH, Fonseca NG, Martelli DRB, Bonan PRF, Almeida LKY, Melo LA, et al. Orofacial manifestations in patients with sickle cell anemia. Quintessence International 2011;42(8):701-9.

\section{Modell 2008}

Modell B, Darlison M. Global epidemiology of haemoglobin disorders and derived service indicators. Bulletin of the World Health Organization 2008; Vol. 86, issue 6:480-7.

\section{O'Rourke 1990}

O'Rourke C, Mitropoulos C. Orofacial pain in patients with sickle cell disease. British Dental Journal 1990;169(5): 130-2.

\section{Oluwatosin 2009}

Oluwatosin SO, Folakemi OA, Edamisan TO. Orthodontic management of traumatic avulsion of permanent incisors in a child with sickle cell anaemia: a case report. Cases Journal 2009;2:8123-9.

Passos 2012

Passos CP, Santos PR, Aguiar MC, Cangussu MC, Toralles MB, da Silva MC, et al. Sickle cell disease does not predispose to caries or periodontal disease. Special Care in Dentistry 2012;32(2):55-60.

\section{Piccin 2008}

Piccin A, Fleming P, Eakins E, McGovern E, Smith OP, McMahon C. Sickle cell disease and dental treatment. Journal of the Irish Dental Association 2008;54:75-79.

\section{Pithon 2011}

Pithon MM. Orthodontic treatment in a patient with sickle cell anemia. American Journal of Orthodontics and Dentofacial Orthopedics 2011;140(5):713-9.

\section{Rada 1987}

Rada RE, Bronny AT, Hasiakos PS. Sickle cell crisis precipitated by periodontal infection:report of two cases. Journal of American Dental Association 1987;114(6): 799-801.

\section{Reisine 1985}

Reisine ST. Dental health and public policy:the social impact of dental disease. American Journal of Public Health 1985;75:27-30.

\section{RevMan 2014 [Computer program]}

The Nordic Cochrane Centre, The Cochrane Collaboration. Review Manager (RevMan). Version 5.3. Copenhagen: The Nordic Cochrane Centre, The Cochrane Collaboration, 2014.

Rinchuse 2007

Rinchuse DJ, Rinchuse DJ, Sosovicka MF, Robison JM, Pendleton R. Orthodontic treatment of patients using bisphosphonates: a report of 2 cases. American Journal of Orthodontics and Dentofacial Orthopedics 2007;131(3): 321-6.

Rouse 1979

Rouse LE, Hays GL. Dental considerations in sickle cell anaemia. General Dentistry 1979;27(6):18.

\section{Sams 1990}

Sams DR, Thornton JB, Amamoo PA. Managing the dental patient with sickle cell anemia: a review of the literature. Pediatric Dentistry 1990;12(5):316-20. 


\section{Schünemann 2011}

Schünemann HJ, Oxman AD, Vist GE, Higgins JPT, Deeks JJ, Glasziou P, et al on behalf of the Cochrane Applicability and Recommendations Methods Group. Chapter 12: Interpreting results and drawing conclusions. In: Higgins JPT, Green S (editors). Cochrane Handbook for Systematic Reviews of Interventions Version 5.1.0 [updated March 2011]. The Cochrane Collaboration, 2011. Available from www.cochrane-handbook.org.

\section{Scipio 2001}

Scipio JE, Al-Bayaty HF, Murti PR, Matthews R. Facial swelling and gingival enlargement in a patient with sickle cell disease. Oral Diseases 2001;7(5):306-9.

\section{Shroyer 1991}

Shroyer JV 3rd, Lew D, Abreo F, Unhold GP. Osteomyelitis of the mandible as a result of sickle cell disease. Report and literature review. Oral Surgery, Oral Medicine, and Oral Pathology 1991;72(1):25-8.

\section{Smith 1986}

Smith DB, Gelbman J. Dental management of the sickle cell anaemia patient. Clinical Preventative Dentistry 1986;8 (2):21-3.

\section{Soni 1966}

Soni N. Microradiographic study of dental tissues of sickle cell anaemia. Archives of Oral Biology 1966;11(6):556-64.

\section{Stanley 2013}

Stanley AC, Christian JM. Sickle cell disease and perioperative considerations: review and retrospective report. Journal of Oral and Maxillofacial Surgery 2013;71 (6):1027-33.

\section{Sterne 2011}

Sterne J, Egger M, Moher D, on behalf of the Cochrane Bias Methods Group. Chapter 10: Addressing reporting biases. In: Higgins JPT, Green S (editors). Cochrane

Handbook for Systematic Reviews of Interventions Version 5.1 [updated March 2011]. The CochraneCollaboration, 2011. Available from www.cochrane-handbook.org.

\section{Taylor 1995}

Taylor LB, Nowak AJ, Giller RH, Casamassimo PS. Sickle cell anemia: a review of dental concerns and a retrospective study of dental and bony changes. Special Care in Dentistry 1995;15(1):38-42.

\section{Weatherall 2010}

Weatherall DJ. The inherited diseases of hemoglobin are an emerging global health burden. Blood 2010;115(22): 4331-6.

\section{Wison Schaeffer 1999}

Wison Schaeffer JJ, Gil KM, Burchinal M, Kramer KD, Nash KB, Orringer E, et al. Depression, disease severity, and sickle cell disease. Journal of Behavioral Medicine 1999; 22(2):115-26.

\section{Yawn 2014}

Yawn BP, Buchanan GR, Afenyi-Annan AN, Ballas SK, Hassell KL, James AH, et al. Management of sickle cell disease: summary of the 2014 evidence-based report by expert panel members. JAMA 2014;312(10):1033-48.

\section{Zahrowski 2009}

Zahrowski JJ. Optimizing orthodontic treatment in patients taking bisphosphonates for osteoporosis. American Journal of Orthodontics and Dentofacial Orthopedics 2009;135(3): 361-74.

* Indicates the major publication for the study 


\section{DATA ANDANALYSES}

This review has no analyses.

\section{AP PENDICES}

\section{Appendix I. Glossary of terms}

\begin{tabular}{|c|c|}
\hline Term & Explanation \\
\hline aplastic crisis & temporary cessation of red cell production \\
\hline exon & portion of a gene that codes for amino acids \\
\hline gingivitis & inflammation of the gingiva as a response to bacterial plaque on adjacent teeth \\
\hline homozygous & having identical pairs of genes for any given pair of hereditary characteristics \\
\hline hypomineralization & $\begin{array}{l}\text { a condition affecting the enamel of the permanent teeth and characterized by a deficiency of minerals; normal } \\
\text { enamel is white and very hard, but hypomineralized enamel is creamy, yellow or brown in colour and is chalky } \\
\text { in texture. As a result teeth look different in appearance, they also undergo wear and are at higher risk of } \\
\text { developing decay }\end{array}$ \\
\hline hypoxia & this is when the body doesn't have enough oxygen \\
\hline intracellular & within a cell \\
\hline malocclusion & a 'poor bite', misaligned teeth between the top and bottom jaws \\
\hline morphology & the form and structure of an organism or any of its parts \\
\hline odontogenic & of, or relating to, the formation and development of teeth \\
\hline oral mucosa & $\begin{array}{l}\text { the mucous membrane lining the inside of the mouth, including lining on the gums, the palate, the lip, the } \\
\text { cheek, the floor of the mouth and other structures }\end{array}$ \\
\hline orofacial & relating to the mouth and face \\
\hline osteomyelitis & inflammation of the bone marrow and adjacent bone \\
\hline periodontitis & $\begin{array}{l}\text { a serious gum infection that damages the soft tissue and destroys the bone that supports your teeth; if inflam- } \\
\text { mation of the gum tissue (gingivitis) is not treated periodontitis can develop }\end{array}$ \\
\hline
\end{tabular}


(Continued)

\begin{tabular}{ll}
\hline polymerize & $\begin{array}{l}\text { a process through which relatively small molecules, called monomers, combine chemically to produce a very } \\
\text { large chainlike or network molecule, called a polymer }\end{array}$ \\
\hline sequestration crisis & $\begin{array}{l}\text { a condition affecting people with sickle cell anaemia which results from the trapping of large amounts of red } \\
\text { cells in the spleen and sometimes in the liver so they are withdrawn from the blood in circulation leading to a } \\
\text { sharp drop in haemoglobin levels }\end{array}$ \\
\hline vaso-occlusive & relating to, resulting from, or caused by occlusion of a blood vessel \\
\hline
\end{tabular}

\section{Appendix 2. Multiple databases search strategy}

\begin{tabular}{|c|c|c|c|c|c|c|}
\hline & SEARCH SITE & $\begin{array}{l}\text { Date of search: } \\
\text { From inception to }\end{array}$ & Type of Search & Keywords used & Results & Relevant RCTs from results \\
\hline \multirow[t]{3}{*}{1} & \multirow{3}{*}{$\begin{array}{l}\text { Google Scholar } \\
\text { ( } \\
\text { scholar.google.com/, }\end{array}$} & \multirow[t]{3}{*}{03 March 2016} & \multirow[t]{3}{*}{ Advanced } & $\begin{array}{l}\text { allintitle: sickle } \\
\text { dental trial }\end{array}$ & 0 & 0 \\
\hline & & & & allintitle: sickle trial & 257 & 0 \\
\hline & & & & $\begin{array}{l}\text { allintitle: sickle den- } \\
\text { tal }\end{array}$ & 57 & 0 \\
\hline \multirow[t]{6}{*}{2} & \multirow{6}{*}{$\begin{array}{l}\text { WHO ICTRP } \\
\text { (www.who.int/ } \\
\text { ictrp/search/en/) }\end{array}$} & \multirow[t]{2}{*}{03 March 2016} & \multirow[t]{2}{*}{ Basic } & sickle dental & 0 & 0 \\
\hline & & & & Sickle oral & 0 & 0 \\
\hline & & \multirow[t]{4}{*}{03 March 2016} & \multirow[t]{4}{*}{ Advanced } & $\begin{array}{l}\text { Sickle cell } \\
\text { AND dental AND } \\
\text { treatment } \\
\text { Sickle cell AND oral } \\
\text { AND treatment }\end{array}$ & 0 & 0 \\
\hline & & & & $\begin{array}{l}\text { Sickle cell AND } \\
\text { dental oral }\end{array}$ & 0 & 0 \\
\hline & & & & $\begin{array}{l}\text { Sickle cell AND } \\
\text { dental }\end{array}$ & 1 & 0 \\
\hline & & & & $\begin{array}{l}\text { Sickle cell } \\
\text { AND dental AND } \\
\text { treatment }\end{array}$ & 1 & 0 \\
\hline 3 & $\begin{array}{l}\text { ClincialTrials.gov } \\
\text { (ClinicalTrials.gov) }\end{array}$ & 03 March 2016 & Basic & $\begin{array}{l}\text { "sickle cell" AND } \\
\text { "dental" }\end{array}$ & 0 & 0 \\
\hline
\end{tabular}




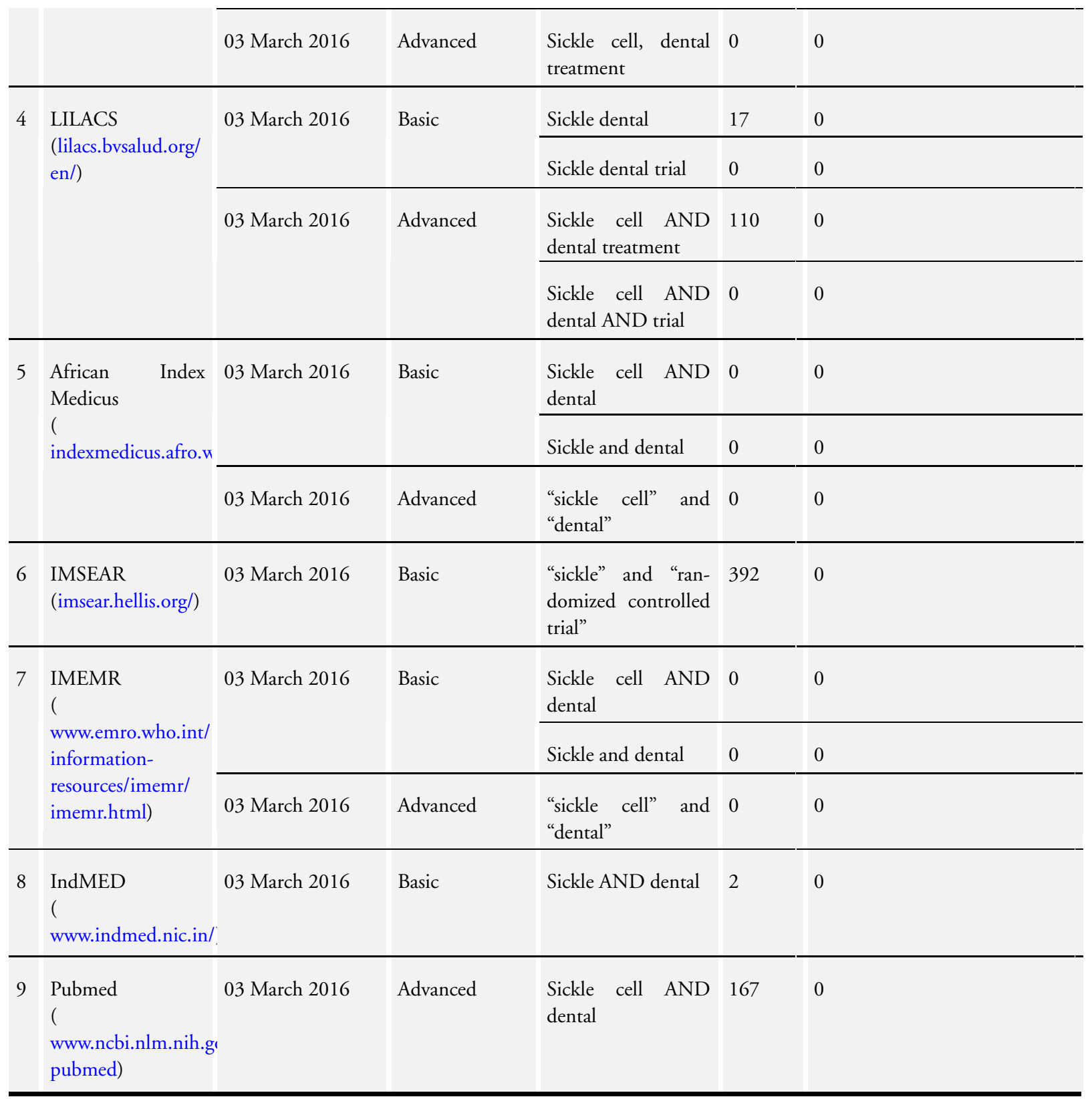




\section{CONTRIBUTIONSOFAUTHORS}

Conceiving the protocol: PM, LK

Designing the protocol: PM, SB, LK, ABL

Coordinating the protocol: PM

Designing search strategies: PM, SB, LK

Writing the protocol: PM, SB, LK, ABL

Providing general advice on the protocol: SB, LK, ABL

\section{DECLARATIONSOF INTEREST}

All authors: none known.

\section{SOURCES OF SUPPORT}

\section{Internal sources}

- No sources of support supplied

\section{External sources}

- National Institute for Health Research, UK.

This systematic review was supported by the National Institute for Health Research, via Cochrane Infrastructure funding to the Cochrane Cystic Fibrosis and Genetic Disorders Group. 